\title{
Ophthalmic manifestations of tuberous sclerosis: a population based study
}

\author{
S A Rowley, F J O’Callaghan, J P Osborne
}

\begin{abstract}
Backgroundlaims-Tuberous sclerosis complex (TSC) has retinal and nonretinal ophthalmic manifestations. This study was designed to determine the prevalence of the ophthalmic manifestations and of refractive errors in a population of patients with TSC.

Methods-179 patients identified were in a prevalence study of TSC in the south of England and 107 of these agreed to full ophthalmic examination which was successful in 100. Ophthalmic examination included examination of the eyelids, cover test, examination of the irides, dilation funduscopy using both direct and indirect ophthalmoscopy, and refraction using retinoscopy. Myopia was defined as a spherical equivalent $<-0.5 \mathrm{D}$ and hyper-

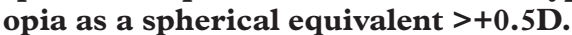

Results-Retinal hamartomas were seen in 44 of the 100 patients. The commonest morphological type of hamartoma seen was the flat, translucent lesion in 31 of the 44 patients $(70 \%)$. The multinodular "mulberry" lesion was seen in 24 of the 44 patients $(55 \%)$ and the transitional type lesion was seen in four of the 44 patients (9\%). Punched out areas of retinal depigmentation were seen in 39 of the 100 patients but only six of 100 controls. $27 \%$ of eyes were myopic, $22 \%$ were hyperopic, and $27 \%$ had astigmatism $>0.75 \mathrm{D}$. Of the non-retinal findings, 39 patients had angiofibromas of the eyelids, five had nonparalytic strabismus, and three had colobomas.
\end{abstract}

Conclusion-Apart from the higher prevalence of flat retinal hamartomas, the findings of this study compare closely with previous large clinic based series of TSC patients. Refractive findings were similar to previous studies of a similarly aged non-TSC population. This is the first series to document the statistically significant association of punched out chorioretinal depigmentation with TSC and the authors believe that it should be looked for as an aid to diagnosis.

(Br f Ophthalmol 2001;85:420-423)

Tuberous sclerosis complex (TSC) is a multisystem disorder characterised by hamartomatous growths that can occur in almost any organ or tissue. The first description of TSC is usually attributed to Bourneville in $1880^{1}$ and in 1908, Vogt described the classic triad of epilepsy, mental retardation, and adenoma sebaceum (now called angiofibromatosis). ${ }^{2}$ The clinical manifestations of TSC are now known to be far more diverse and a more inclusive system of primary and secondary diagnostic criteria have been introduced. ${ }^{3}$ These include cortical tubers, retinal astrocytomas, facial angiofibromas, ungual fibromas, hypomelanotic skin lesions, shagreen patch, and renal angiomyolipomas.

Ophthalmic features associated with TSC can be divided into retinal and non-retinal. The retinal associations of TSC were first noted by Van der Hoeve in $1921 .^{4}$ He termed these lesions phakomas (derived from the greek phakos, meaning spot) and introduced the concept of phakomatosis. These retinal lesions are now known to be astrocytic hamartomas. $^{5}$

Three basic morphological types of retinal hamartomas are described in the literature ${ }^{6}$ : (i) the relatively flat, smooth, non-calcified, grey, translucent lesion (Fig 1A); (ii) the elevated, multinodular, calcified, opaque lesion resembling mulberries (Fig 1B); and (iii) a transitional lesion which has morphological features of both of the previous. Other retinal findings include retinal pigmentary disturbance ranging from hyperpigmented areas (probably congenital retinal pigment epithelium hypertrophy) ${ }^{7}$ to "punched out" hypopigmented areas at the posterior pole or midperiphery (Fig 1C). ${ }^{89}$ Non-retinal findings include angiofibromas of the eyelids, coloboma of the iris, lens and choroid, strabismus, poliosis of eyelashes, papilloedema, ${ }^{7}$ and sector iris depigmentation. ${ }^{9}$

Previous studies ${ }^{61011}$ have examined the prevalence of ophthalmic manifestations of TSC in clinic based studies in the USA and Japan, but this is the first population based study examining the prevalence in a UK based population.

\section{Materials and methods}

The study population encompassed Avon, Wiltshire, Southampton and south west Hampshire, Portsmouth and south east Hampshire, Winchester, and Dorset as part of the Wessex Tuberous Sclerosis epidemiology study undertaken by FJO. Multicentre ethics committee approval was obtained. Patients with TSC were identified by various methods: (i) written contact with consultants likely to encounter individuals with TSC, including paediatricians, neurologists, ophthalmologists, dermatologists, cardiologists, nephrologists, urologists, neurosurgeons, physicians in learning disorders, geneticists, and general practitioners; (ii) a review of the hospital activity analysis in the study area from 1986 onwards; (iii) information from the Tuberous Sclerosis Association (a support group for patients with TSC). The diagnosis of TSC was confirmed by
Accepted for publication 31 October 2000 


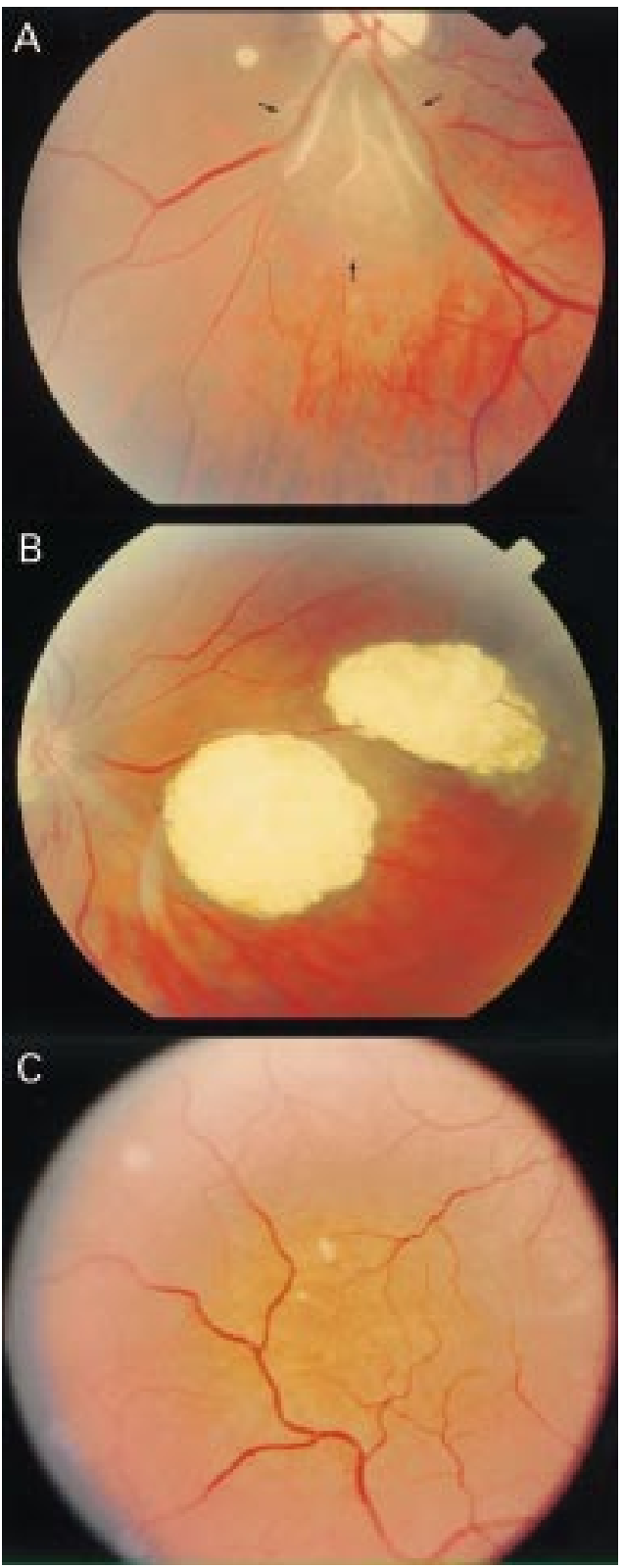

Figure 1 (A) Smooth non-calcified retinal hamartoma (arrowed). (B) Calcified, multinodular retinal hamartomas ("mulberry tumours"). (C) "Punched out" areas of chorioretinal depigmentation.

FJO using the criteria of two independent hamartomas. ${ }^{12}$

The total population in the study area was 3679162 (data from Office of Populations, Census and Surveys, census date 1 August 1998) and from this, 179 patients with TSC were identified giving a prevalence of $4.9 /$ 100000 . Of these 179 patients, 107 agreed to undergo ophthalmic examination.

We performed ophthalmic examination of the eyelids, cover test, examination of the irides, dilated funduscopy using direct ophthalmoscopy and indirect ophthalmoscopy with $20 \mathrm{D}$ lens, and refraction of both eyes using retinoscopy. We classified the retinal hamartomas into the three categories previously described. In order that the refractive results could be compared with previous population studies, ${ }^{13} 14$ myopia was classified as a spherical equivalent $<-0.5 \mathrm{D}$, hyperopia as a spherical equivalent $>+0.5 \mathrm{D}$, and emmetropia as a spherical equivalent between $-0.5 \mathrm{D}$ and $+0.5 \mathrm{D}$. The ophthalmic examinations were all performed by one ophthalmologist (SAR).

\section{Results}

Of the 107 patients who agreed to undergo ophthalmic assessment, full retinal examination was possible in 100 with the other seven patients being unable to cooperate sufficiently owing to their degree of mental impairment. The results which follow relate only to the 100 fully examined patients. The median age of the patients was 27 (range 2-76 years) with 50 male and 50 female patients. The association between age and retinal lesion was analysed by dividing age into quintiles and then using $\chi^{2}$ analysis.

RETINAL FINDINGS

Retinal hamartomas were found in 44 patients and were bilateral in 15 patients $(34 \%)$. In 13 patients $(30 \%)$ there was more than one morphological type of hamartoma present.

The commonest morphological type of hamartoma seen in our series was the flat, smooth translucent lesion which was seen in 31 of the 44 patients $(70 \%)$. Their sizes ranged from 0.25 to 2 disc diameters and they were usually at the posterior pole and frequently were seen to be superficial to retinal vessels.

The classic, multinodular, "mulberry" lesion was seen in 24 of the 44 patients (55\%) and was the second commonest retinal hamartoma in our series. These were always located in the posterior pole and $80 \%$ were on or within 2 disc diameters of the optic disc. Their sizes ranged from 0.25 to 4 disc diameters. The third morphological type of retinal hamartoma, the transitional lesion with features of both of the previous types, was seen in four of the 44 patients $(9 \%)$. In all cases, these were flat hamartomas with a central area of nodular calcification and were located at the posterior pole.

There was no correlation between age and the presence of retinal astrocytic hamartomas overall $\left(\chi^{2} 1.8\right.$ with $\left.4 \mathrm{df}, \mathrm{p}>0.5\right)$. When the individual type of retinal hamartoma was considered, there was again no correlation between age and the three types of retinal hamartoma $\left(\chi^{2} 10.2\right.$ with $\left.4 \mathrm{df}, \mathrm{p}>0.1\right)$.

Punched out areas of chorioretinal hypopigmentation were seen in 39 of the 100 patients examined. The areas were all less than 1 disc diameter in size and were all located in the midperiphery of the retina. When 100 age matched, opportunistically collected, nonTSC controls attending general ophthalmic clinics at the Royal United Hospital were examined, hypopigmented areas were seen in $6 / 100$ patients (SAR, unpublished data). Using the two sided Fisher exact test on our data, there is a statistically significant association between these lesions and TSC $(p<0.001)$. There was no correlation between the presence of chorioretinal hypopigmentation and age $\left(\chi^{2}\right.$ 1.7 with $4 \mathrm{df}, \mathrm{p}>0.5$ ). 
Table 1 Comparison of findings with previous large series

\begin{tabular}{|c|c|c|c|c|c|c|}
\hline Reference & Type of study (size) & $\begin{array}{l}\text { Overall prevalence } \\
\text { of } R H\end{array}$ & $\begin{array}{l}\text { Bilater al } \\
\text { RH }\end{array}$ & Flat $R H$ & Multinodular $R H$ & Transitional RH \\
\hline Current study & Population (100) & $44 \%(34-54)$ & $\begin{array}{l}34 \% \\
(20-48)\end{array}$ & $\begin{array}{l}70 \% \\
(56-84)\end{array}$ & $55 \%(40-70)$ & $9 \%(0-18)$ \\
\hline Mayo Clinic $^{6}$ & Clinic (139) & $49 \%(38-60)$ & $\begin{array}{l}50 \% \\
(38-62)\end{array}$ & $\begin{array}{l}57 \% \\
(45-69)\end{array}$ & $50 \%(38-62)$ & $12 \%(4-20)$ \\
\hline Tokyo $^{9}$ & Clinic (100) & $87 \%(80-94)$ & $\begin{array}{l}86 \% \\
(79-93)\end{array}$ & "almost all" & "less frequent" & Not stated \\
\hline
\end{tabular}

$\mathrm{RH}=$ retinal hamartoma.

$95 \%$ confidence intervals in parentheses.

NON-RETINAL FINDINGS

Angiofibromas of the eyelids were seen in 39 of the 100 patients and non-paralytic strabismus was seen in five patients (four exotropia and one esotropia). Colobomas were seen in three patients. One of these involved only the iris but the other two had iris and choroidal involvement. In two patients, sector depigmentation of the iris was present.

REFRACTION

Reliable refraction was possible in 80 of the 100 patients and in 10 patients, a recent refraction was taken from optometrists' records. As tropicamide $1 \%$ was used in the study, the refraction was not a true cycloplegic refraction. Myopia was present in $48 / 180$ eyes $(27 \%)$, hyperopia was present in 39/180 eyes (22\%), and astigmatism $(>0.75 \mathrm{D})$ was present in $48 / 180$ eyes $(27 \%)$. Anisometropia (>1.0D difference between the two eyes) was found in 10 patients $(11 \%)$.

\section{Discussion}

The prevalence of ophthalmic features of TSC has never been reported in a large population based study before. The prevalence of TSC associated retinal astrocytic hamartomas in previous clinic based studies varies from $3 \%{ }^{15}$ to $100 \%,{ }^{10}$ but the largest reported series from the Mayo Clinic ${ }^{6}$ gives an overall prevalence of $49 \%$. Comparisons of our series with previously reported large series of retinal findings in TSC are shown in Table 1.

We found no correlation between age and type of retinal hamartoma which supports previous findings that most retinal lesions in tuberous sclerosis remain stable over time. ${ }^{16}$ The commonly held belief that flat hamartomas evolve into the multinodular type is therefore likely to be incorrect.

Although "punched out" areas of chorioretinal depigmentation have been noted in previous series ${ }^{61017}$ their significance to TSC was uncertain. In a smaller series of patients from the same region, ${ }^{17}$ they were seen in 15 of 19 patients with TSC and in none of 19 age and sex matched non-TSC controls. In our larger series, compared with an age matched nonTSC population, we have shown a statistically significant association between these lesions and TSC, and we believe that "punched out" areas of chorioretinal depigmentation could be used to aid diagnosis in patients suspected of having TSC. We found no correlation between age and these areas of chorioretinal depigmentation which was also found in the previous series. ${ }^{17}$
Of the non-retinal findings, angiofibromas of the eyelids were the commonest being present in 39 of 100 patients. Non-paralytic strabismus was seen in five of 100 patients and colobomas were present in three patients, one involving iris alone and the other two also involving choroid.

This is the first study to report on the refraction of patients with TSC. The definitions of myopia and hyperopia were chosen so that comparisons could be made with previous data from normal populations. ${ }^{1314}$ The age of the patients in these studies, however, is older than our series and it is difficult to make comparisons with similarly aged populations owing to differing definitions of types of refractive error and differing methods of refraction. Overall, $27 \%$ of eyes were myopic $(<-0.5 \mathrm{D}), 22 \%$ of eyes were hyperopic $(>+0.5 \mathrm{D})$, and $51 \%$ were emmetropic. This compares with $25 \%$ myopia prevalence in the similarly aged sample from the National Health and Nutrition Examination Survey (NHANES), ${ }^{18} 15 \%$ myopia, and $57 \%$ hyperopia in the older sample from the Blue Mountains Eye Study, ${ }^{13}$ and $26 \%$ myopia and $49 \%$ hyperopia in the older Beaver Dam study population. ${ }^{14}$ In a similarly aged Finnish population $^{19}$ the prevalence of myopia was $11.5 \%$ and of hyperopia was $28.3 \%$, although their definition was spherical equivalent of $+2 \mathrm{D}$ or more. If this definition were applied to our population, the prevalence of hyperopia would be $8 \%$.

Approximately $50 \%$ of TSC patients have some degree of mental impairment ${ }^{20}$ and in our study population $35 \%$ had moderate to severe mental impairment. Given that myopia has been associated with educational achievement, ${ }^{1921}$ it is interesting to note that the prevalence of myopia in our sample of TSC patients is greater than that seen in other similarly aged normal populations.

The prevalence of astigmatism was $27 \%$ (0.5-4.5D) compared with $20 \%$ in Danish study of hospital patients aged $16-85^{22}$ and $10 \%$ in the Finnish population above. ${ }^{19}$ The prevalence of anisometropia ( $>1.25 \mathrm{D}$ difference between the two eyes) was $11 \%$ in our study compared with $7.1 \%$ in the Finnish study ${ }^{19}$ and $9 \%$ in the Danish study. ${ }^{22}$

In summary, this is the first population based study documenting the prevalence of ophthalmic manifestations in patients with TSC and the refraction of these patients. The fundal findings compare closely with previous large clinic based studies apart from a higher prevalence of flat hamartomas in our study group. This is also the 
first large series to document the statistically significant association of "punched out" chorioretinal depigmentation in TSC patients. The refractive errors of patients with TSC are broadly similar to those described in previous population studies of normal individuals.

1 Bourneville DM. Sclerose tubereuse der circonvolutions cerebrales: idiotie et epilepsie hemiplegique. Arch Neurol (Paris) 1880;1:81-91.

2 Vogt $\mathrm{H}$. Zur diagnostik der tuberosen sclerose. $Z$ Erforsch Benhandl fugendl Schwachsinns 1908;2:1-16.

3 Roach ES, Gomez MR, Northrup H. Tuberous sclerosis complex consensus conference: revised clinical diagnostic criteria. 7 Child Neurol 1998;13:624-8.

4 Van der Hoeve J. Augengeschwultse bei der tuberosen Hirnsklerose (Bourneville). Albrecht von Graefes Arch Klin Ophthalmol 1921;105:880-98.

5 Kinder RSL. The ocular pathology of tuberous sclerosis. $\mathcal{F}$ Paediatr Ophthalmol 1972;9:106-7.

6 Robertson DM. Ophthalmic findings. In: Gomez MR, ed. Tuberous sclerosis complex. 3rd ed. New York: Oxford Tuberous sclerosis complex. 3r.

7 Robertson DM. Ophthalmic manifestations of tuberous sclerosis. Ann NY Acad Sci 1991;615:17-25.

8 Nyboer JH, Robertson DM, Gomez MR. Retinal lesions in tuberous sclerosis. Arch Ophthalmol 1976;94:1277-80.

9 Lucchese NJ, Goldberg MF. Iris and fundus pigmentary changes in tuberous sclerosis. If Paediatr Ophthalmo Strabismus 1981;18:45-6.

10 Shelton RW. The incidence of ocular lesions in tuberous sclerosis. Ann Ophthalmol 1975;7:771-4.
11 Kiribuchi K, Uchida Y, Fukuyama Y. High incidence of fundus hamartomas and clinical significance of a fundus score dus hamartomas and clinical significance of a fundus
in tuberous sclerosis. Brain Devel 1986;8:509-17.

12 O'Callaghan FJ, Osborne JP. Advances in the understanding of tuberous sclerosis. Arch Dis Child 2000;83:140-2.

13 Attebo K, Ivers RQ, Mitchell P. Refractive errors in an older population - the Blue Mountains Eye Study. Ophthalmology 1999;106:1066-71.

14 Wang Q, Klein BEK, Klein R, Moss SE. Refractive status in the Beaver Dam Eye Study. Invest Ophthalmol Vis Sci 1994; 35:4344-7.

15 Critchley M, Earl CJ. Tuberous sclerosis and allied conditions. Brain 1932;55:311-46.

16 Zimmer-Galler IE, Robertson DM. Long-term observation of retinal lesions in tuberous sclerosis. Am $\mathcal{f}$ Ophthalmol 1994;119:318-24.

17 Walters RF, Denning AM, Webb DWM, et al. Punched out chorioretinal defects in tuberous sclerosis, is this a new diagnostic sign? Presented as a poster at Royal College of Ophthalmologists Annual Congress, 1998.

18 Sperduto RD, Seigel D, Roberts J, et al. Prevalence of myopia in the United States. Arch Ophthalmol 1983;101:405-7.

19 Aine E. Refractive errors in a Finnish rural population. Acta Opthalmol (Copenh) 1984;62:944-54.

20 Webb DW, Fryer AE, Osborne JP. Morbidity associated with tuberous sclerosis: a population study. Devel Med Child Neurol 1996;38:146-55.

21 Teasdale TW, Fuchs J, Goldschmidt E. Degree of myopia in relation to intelligence and educational level. Lancet 1988; 2:1351-4.

22 Fledius HC. Prevalences of astigmatism and anisometropia in adult Danes. With reference to presbyopes' possible use of supermarket standard glasses. Acta Ophthalmol (Copenh) 984;62:391-400

\section{Video Reports (www.bjophthalmol.com)}

Capsule staining and mature cataracts: a comparison of indocyanine green and trypan blue dyes. $D F$ Chang

Pearls for implanting the Staar toric IOL. D F Chang 